\title{
Research of City Rainstorm Waterlogging Scene Simulation -- in Daoli District of Harbin City as an Example Peng Chen ${ }^{1}$, Jiquan Zhang ${ }^{2}$, Lingfeng Zhang ${ }^{1}$, Yingyue Sun ${ }^{1}$
}

\author{
1. College of Tourism and Geographical Sciences, Jilin Normal University, Siping 1360003, China
}

2. School of Environment, Northeast Normal University, Changchun 130117, China

Received 3 September 2014

Accepted 15 February 2015

\begin{abstract}
As global warming urbanization process accelerated, urban waterlogging problem is increasingly serious, has become the research hotspot nowadays. City rainstorm waterlogging scene simulation is one of the important link in the research of the process in which residents shelter when city rainstorm waterlogging occurred. To develop urban rainstorm product scenario simulation study can guide us to determine the product elimination and influence range and location. This study using a one-dimensional and two-dimensional unsteady flow as the basic equation, with irregular grid as the basic frame, build urban rainstorm waterlogging deposition numerical simulation model, combining with the information diffusion theory calculation rainstorm probabilities in the study area, on this basis, set the study area rainstorm waterlogging situation, realized the different waterlogging scene simulation and visualization. The results show that the heavy rain that just sccumulate waterlogging disasters occurs once every five years in the study area, and depth of $0-0.47 \mathrm{~m}$, velocity between $0-0.43 \mathrm{~m} / \mathrm{s}$.there is the biggest produce waterlogging which sccumulate with the heavy rain occurs once every 100 years, and the depth of $0-3 \mathrm{~m}$,velocity between $3-3.4 \mathrm{~m} / \mathrm{s}$.
\end{abstract}

Keywords: Harbin; rainstorm waterlogging disaster; scenario simulation

\author{
城市暴雨积涝情景模拟研究一以哈尔滨市道里区为例 \\ 陈鹏 ${ }^{1}$, 张继权 ${ }^{2}$, 张立峰 ${ }^{1}$, 孙港悦 ${ }^{1}$ \\ 1. 吉林师范大学旅游与地理科学学院, 四平 136000 , 中国 \\ 2. 东北师范大学环境学院, 长春 130117 , 中国
}

\begin{abstract}
摘要: 随着全球气候变暖、城市化进程加快, 城市积涝问题日趋严重, 已经成为当今研究热点。城市暴雨 积涝灾害居民避难迁安研究过程中, 城市暴雨积涝情景模拟是其重要环节之一。开展城市暴雨积涝情景模 拟研究可以指导我们确定积涝影响范围及发生位置。本研究利用一、二维非恒定流为基本控制方程, 以不 规则网格为基本骨架, 构建城市暴雨积涝数值模拟模型, 并对研究区降雨过程分析与强度计算, 以此为基 础设定研究区暴雨积涝情景, 实现了不同积涝情景模拟结果及可视化。研究结果表明当研究区发生 5 年一 遇的暴雨时区内刚好发生积涝灾害, 且水深为 $0-0.47 \mathrm{~m}$ 之间, 流速在 $0-0.43 \mathrm{~m} / \mathrm{s}$ 之间; 100 年一遇的暴雨时 区内积港为最大，且水深在 $0-3 \mathrm{~m}$ 之间，流速在 $0-3.4 \mathrm{~m} / \mathrm{s}$ 之间。
\end{abstract}

关键词: 哈尔滨; 暴雨积涝灾害; 情景模拟

\section{1. 引言}

随着全球气候变暖和城市化进程不断加快, 未来 城市暴雨积涝灾害发生频率将越来越高。从历史城市 暴雨积涝灾害统计可知, 城市道路积水深度可达 1.5-3.0m, 车辆、行人无法正常通行, 地下设施被淹,

作者简介: 陈鹏（1980-), 男, 讲师, 博士, 从事自然灾害 风险评价与管理研究.E-mail: pp11290@163.com
负一层住户生命受到严重威胁。从2008年到2013年全 国351个城市都发生了不同程度的积涝灾害, 道路积水 深度在 $50 \mathrm{~cm}$ 以上的城市达到 $60 \%$, 积水超过半小时的 占到将近 $80 \%$, 其中城市积涝灾害较重的城市有大连、 北京、武汉、杭州、郑州、天津、哈尔滨等。因此, 开展城市暴雨积涝灾害情景模拟对城市居民避难迁安、 积涝灾害预防预警等具有重要意义 ${ }^{[1]}$ 。近10多年来,

Published by Atlantis Press

Copyright: the authors 
从国际减灾战略到国内自然灾害预防预警等减灾工 作中, 灾害的预防预警尤为重要; 而预防预警的前 提就是灾害的情景模拟, 同时也是城市预防自然灾 害, 控制和降低自然灾害的重要基础性研究 ${ }^{[1]}$ 。通 过搜集与整理现有城市暴雨积涝情景模拟研究发现, 对于积涝模型建立过程多数是以水力学方法、水动 力学方法构建, 且模型多数未考虑地下排水管网或 是简化排水管网, 在计算精度上有所欠缺, 尤其是 对积水流速并未考虑 ${ }^{[2-5]}$ 。因此, 本文针对城市地区 小尺度的暴雨积涝灾害为研究对象, 结合哈尔滨市 道里区实证研究, 提出了一套完整的城市暴雨积涝 情景模拟思路与方法, 创建了城市暴雨积涝情景模 拟模型与范式, 以充实、完善小尺度城市自然灾害 应急理论与方法, 为我国制订城市暴雨积涝灾害应 急管理和规划提供依据。本文研究与当前国际上很 多大城市开展的基于小尺度的灾害应急管理趋势相 一致, 也是确保大尺度城市灾害应急管理及评估精 度的前提和基础。

\section{2. 研究区概况}

\section{1. 自然概况}

研究区位于东经 $125^{\circ} 42^{\prime}-130^{\circ} 10^{\prime}$ ，北纬 $44^{\circ} 04^{\prime}-46^{\circ} 40^{\prime}$, 黑龙江省省会, 副省级城市。 市内总体地形为南高北低, 西高东低。江南城区地 貌属于堆积和剥蚀堆积类型, 内河切割松花江阶地 和漫滩地, 形成了起伏变化的地貌。同时, 区内由 于近些年超采地下水导致部分区域地面下降, 道路 极易积水。市内多年平均降水量 $545.7 \mathrm{~mm}$, 流域内 持续时间长、雨量较大、影响范围广的大暴雨发生 时间多集中在 $7 、 8$ 两个月份, 出现次数占大暴雨总 数的 84-88\%, 可见 7、8 月份是暴雨频发期。汛期 6-9 月份降水量占全年降水量的 80\%, 其中 7、8 月 占 $52 \%$, 此期间极易形成暴雨积涝灾害。

\section{2. 研究区积涝灾害概况}

近几年哈尔滨城市化进程较快, 不论是新城区 还是老城区都存在着排水管道偏少, 管渠断面过小, 截止今年, 哈尔滨市排水管线共有 993 公里, 排水 管网覆盖率只有 $66 \%$, 还有 $34 \%$ 地区没有排水设施。 市内排水管网的排水能力为 $117 \mathrm{~m}^{3} / \mathrm{s}$, 比中雨的排 水能力低 $68 \mathrm{~m}^{3}$ 。一遇中雨, 每秒就会有 $68 \mathrm{~m}^{3}$ 雨水因 无法即排而停留在路面上, 降雨超过半小时以上, 哈尔滨市一些街道就会积水。

\section{3. 数据来源}

本研究所需数据中气象资料来自黑龙江省气象 局多年降雨数据（1961-2009), 空间数据采用高分 辨率快鸟影像 (分辨率 $0.61 \mathrm{~m}$ ), 以及道里区排水管 网数据。所需城市下垫面基础信息从快鸟影像数据 中提取, 其中包括道路信息、居民点信息、地面鉌 率、面积等参数, 所用数据均利用 ARCGIS 软件中的 空间分析工具进行分析和提取。

\section{3. 城市暴雨积涝数值模拟}

\section{1. 研究区集水区确定}

集水区是指将某一流域与另一流域分开的分水 岭, 包括对一河流或湖泊供应水源的全部区域或地 区。而事实上因地质, 地下水等诸多因素影响, 无 法仅以简单的面积来确定, 同时人为的改变, 如城 市下垫面变为水泥路、柏油路等, 其产汇流时间、 方向及下渗能力都有所改变。所以确定某一区域集 水区域时必须以数字高程模型 (DEM) 为基准, 利用 ARCGIS 软件中的水文分析功能模块生成水流流向 图。由于城市下垫面特点, 本模型中对于水流形成 过程中只考虑水流受重力影响情况。根据 ARCGIS 软件提取结果把研究区分成 2645 个积水区域, 并结 合道里区的行政边界所涉及到的各积水区域进行整 合。

\section{2. 道里区降雨时程分析}

一次降雨过程由于不同区域、不同降雨过程, 从而导致一次降雨过程的雨峰出现的时段不同。当 一次降雨过程中雨峰出现时, 则是降雨量最多时刻, 此时刻对于城市积涝来说是最严重时段。所以, 要 想了解城市暴雨积涝的形成过程, 必须了解一次降 雨过程中的降雨时程分配。通过对研究区历史降雨 过程统计分析得出哈尔滨的降雨时程分配特点。依 据分析结果对研究区降雨过程作了五种雨型概化。 分别是雨峰 0.4 处、雨峰 0.6 处的雨峰靠前、雨峰 靠后、均匀雨峰、雨峰前置、雨峰后置 (图 1)。

\section{3. 排水分区及排水设施概化}

\section{1. 排水分区确定}

排水分区是城市暴雨积涝模型中不可缺少的重 要组成部分, 其中主要考虑排水地区的地形、水系、 水文地质、容泄区水位和行政区划等因素。其划分 
原则: (1)排水分区划分应根据城市总体规划布局, 结合城市废水受纳体位置进行划分; (2) 排污系统 需根据城市规划并且结合坚向规划及城市路网、污 水受纳体和污水处理厂分布位置进行合理布局; (3) 雨水系统应布局应根据城市已有规划及地形, 结合 坚向规划和城市废水受纳体位置, 按照流域划分及 布局;（4）雨污混排系统应综合雨水、污水、泵站、 污水系统布局的要求, 并考虑截流干管 (渠) 和溢 流井位置进行合理布局。在哈尔滨城市排水规划中, 研究区分属于沿江排水分区与何家沟排水分区（图 2)。
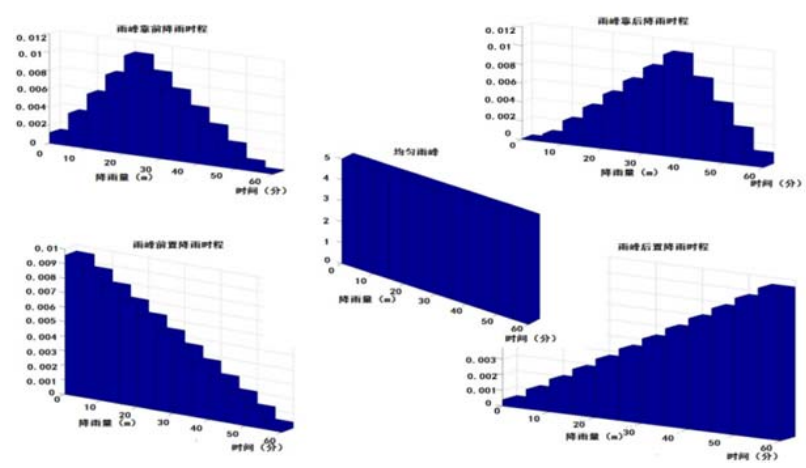

图 1. 研究区降雨时程分配

通过对哈尔滨市道里区以划分的排水分区分析 可知, 已有的两个排水分区不能满足城市暴雨积涝 模型需要。现有的两个排水分区从模型精度上考虑 不能满足模型模拟的精度, 为了提高模型模拟的精 度, 对排水区进行了重新划分。结合上述排水分区 原则, 根据管道走向以及排水口位置, 概化多个排 水小区, 以适应排水计算需要 (图 3)。

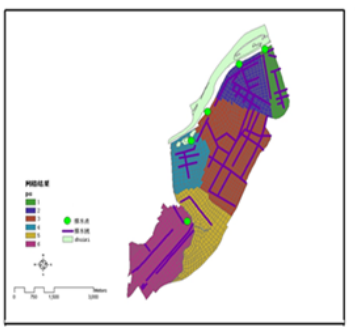

图 2. 道里区现状排水分区

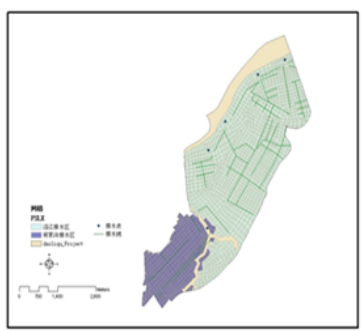

图 3. 道里区重分排水分区

\section{2. 排水管网概化}

城市中排水管网分布及其复杂、纵横交错, 不 同城市排水管网建设进度也不一样。随着城市化进 程加快, 排水管网建设远远不能满足城市发展需要。
一般的城市排水管网构成由排水管道、水井、明沟、 泵站等组成, 其中雨水井承担接收地面来水。排水 管道中积水是由排水泵站、闸或淹没出流管道来实 现, 城市的一级、二级河道、明沟和坑塘、湖泊接 纳泵站、闸门、或淹没出流管道的来水 ${ }^{[6]}$ 。研究区 的城市排水图来自于哈尔滨城市排水总体规划 (CAD 格式)。通过 GIS 的数据处理功能, 对其格式、坐标 投影进行转换。处理成为与其它数据相同的格式 (shape 格式)。由于城市排水规划图只有干管信息, 所以本研究只考虑干管排水概化。

\section{2. 城市下垫面概化与网格划分}

城市下垫面地物概化过程非常复杂, 对于连续 性阻水建筑物 (如立铁路、房屋、交桥、堤防、高 于地面的街道) 在概化时需进行特殊考虑。本研究 中并没有设置节点, 同时对于城内的二级河流, 也 并未概化成为特殊通道, 而是按照其实际宽度概化 成尺度比较小的网格, 分别在网格和通道属性中注 明 $^{[7-9]}$ 。其它设施如阻水建筑、排水设施等, 也分别 在网格和通道属性中注明 (图 4-图 5)。由于网格与 通道都是实体, 都可以储存数据, 并已建立拓扑关 系, 研究区共划分网格 1724 个, 通道 3572 条。在 对研究区下垫面概化时结合网格划分特点, 将研究 区概化为含排水管网的不规则网格、含阻水建筑物 不规则网格、不含阻水建筑物不规则网格等。

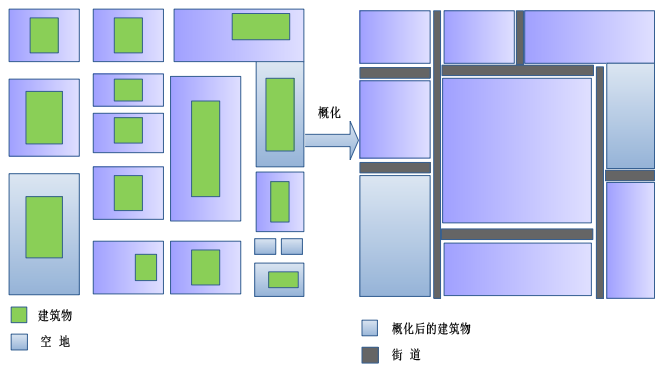

图 4. 研究区下垫面概化

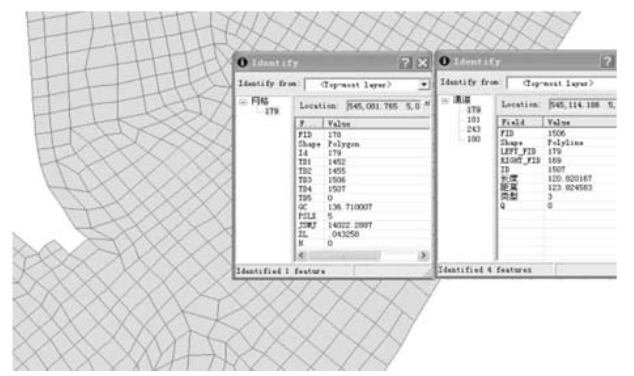

图 5. 研究区网格和通道及其属性 


\section{4. 城市暴雨积涝模型构建}

\section{1. 模型控制方程}

目前国内外针对城市道路积水的数值模拟方法 较多, 但大多数只是模拟出水深, 对于流速、流向 并未计算 ${ }^{[10-13]}$ 。当积涝灾害发生时, 道路积水、流 速对居民水中行走都会产生影响, 因此, 需考虑水 深对居民出行影响程度, 又兼顾考虑水流速度对居 民出行影响程度。研究中城市暴雨积涝数值模型以 二维非恒定流为基本骨架, 以不规则网格概化地物, 同时结合排水管网中一维非恒定流综合考虑建立暴 雨积涝数值模型。具体由四个大的模块构成, 分别 为产流模型、汇流模型、排水模型以及积涝模型 (图 6)。具体公式如下:

二维非恒定流方程:

连续方程:

$$
\frac{\partial h}{\partial t}+\frac{\partial M}{\partial x}+\frac{\partial N}{\partial y}=0
$$

动量方程:

$$
\begin{aligned}
& \frac{\partial M}{\partial t}+\frac{\partial(u M)}{\partial x}+\frac{\partial(u M)}{\partial y}+g h \frac{\partial H}{\partial x}+\frac{g n^{2} u \sqrt{u^{2}+v^{2}}}{h^{\frac{1}{3}}}=0 \\
& \frac{\partial N}{\partial t}+\frac{\partial(u N)}{\partial x}+\frac{\partial(u N)}{\partial y}+g h \frac{\partial H}{\partial y}+\frac{g n^{2} v \sqrt{u^{2}+v^{2}}}{h^{\frac{1}{3}}}=0
\end{aligned}
$$

式中: $h$ 为水深; $H$ 为水位 $(H=h+Z, Z$ 为下垫 面高程); $q$ 为源汇项, 在模型中代表有效降雨强度; $M 、 N$ 分别为 $x 、 y$ 方向上的单宽流量; $u 、 V$ 分别为 流速在 $x, y$ 方向的分量; $n$ 为粘率系数; $g$ 为重力 加速度; $t$ 为水流在网格内流动时间。

一维非恒定流基本控制方程:

$$
\frac{\partial Q}{\partial t}+\frac{\partial}{\partial l}\left(\frac{Q^{2}}{A}\right)+g A \frac{\partial H}{\partial l}=-g A S_{f}
$$

式中: $Q$ 为截面流量; $A$ 为计算断面的过水面积; $S_{f}$ 为摩阻坡降; $t$ 为积水到达通道时间; 1 为网格通道 长度。

宽顶堰溢流公式:

$$
Q=m \sigma_{s} \sqrt{2 g} H^{3 / 2}
$$

式中: $Q_{j}$ 为堰顶单宽流量; $m$ 为宽顶堰溢流系数;

$Q_{s}$ 为淹没系数; $H_{j}$ 为堰顶水位。

流速计算公式:

$$
V=\sqrt{M^{2}+N^{2}} / h
$$

式中: $V$ 为水流速度; $M 、 N$ 分别为 $x 、 y$ 方向上的单 宽流量; $h$ 为积水深度。

\section{2. 城市道路积水流向提取}

利用 ARCGIS9. 3 软件的水文分析功能利用 DEM 提取地表水流径流水流方向、汇流累积量、水流长 度、河流网络（包括河流网络的分级等）以及对研 究区的流域进行分割等。利用提取的基本水文因子, 结合 DEM 可以再现水流的流动过程, 最终完成水文 分析过程, 并提取研究区各网格内水流方向 (图 7)。

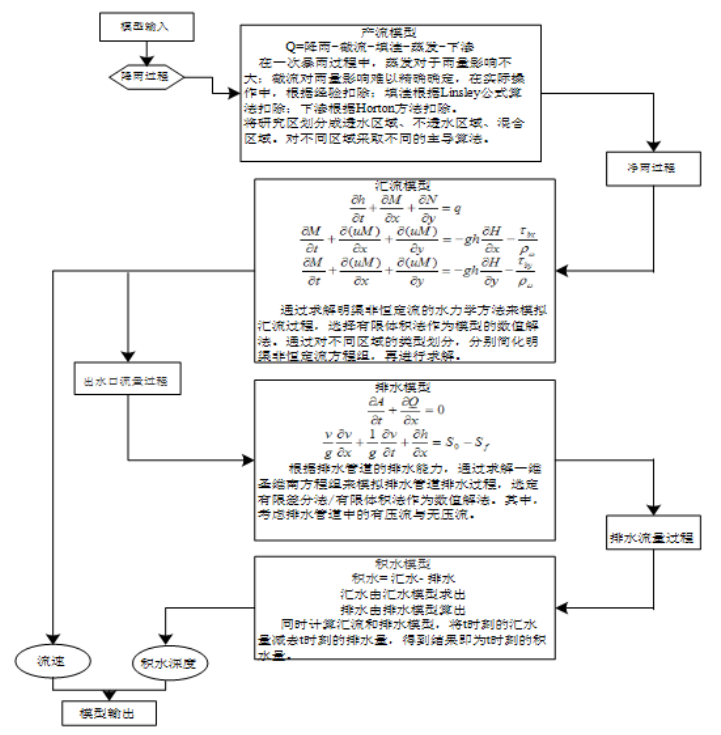

图 6. 城市暴雨积涝模型构建流程

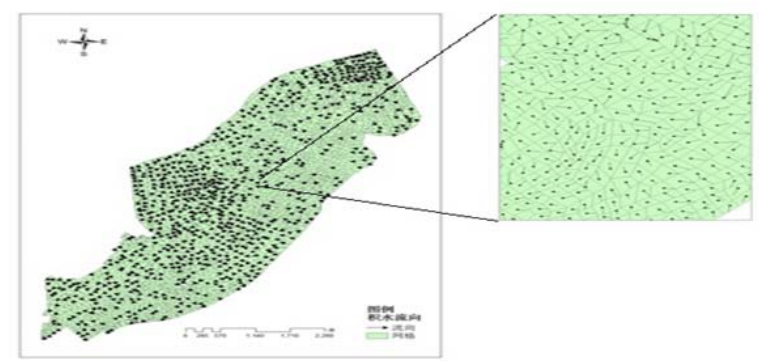

图 7. 研究区水流方向

\section{3. 积涝数值模拟模型构建}

城市暴雨积涝数值模拟模型构建方法多数是利 用集水区的积水量，采用基于 GIS 的 “等体积法”, 模拟城市道路积水区域和淹没深度 ${ }^{[15 、 16]}$ 。本模型在 吸取有限差分法和有限体积法的优点, 在网格周边 计算流量, 在网格形心处计算水位 ${ }^{[17-18]}$, 以提高模 型计算的精度。研究区不规则网格绘制过程是利用 ARCGIS 软件实现的, 绘制后的不规则网格进行属性 赋值, 主要包括高程、初始水深、不规则网格编号、 通道编号、下垫面䊁率等。计算过程中以二维非恒 
定流控制方程为基本方程, 水流方向按照 $\mathrm{x} 、 \mathrm{y}$ 方向 进行分解 (图 8), 通道作为各个网格水流交换的媒 介, 网格内水深为下垫面积水深度。

综合以上城市暴雨积涝数值模拟过程, 利用 ARCGIS 空间数据管理功能集成管理研究需要的空 间信息以及属性信息, 并对研究区域进行水文分析、 城市现状分析。在此基础上划分网格、生成通道, 并通过空间关联, 对网格和通道建立拓扑关系, 通 过空间分析和统计将在模拟所需参数以属性方式分 别赋给通道和网格。通过格式转换, 生成文本文件 提供给计算模块, 计算模块以 $\mathrm{VC}++$ 编程开发, 计算 结果生成文本文件，通过属性关联提供给 ARCGIS 网格和通道图层, 使得计算结果可以可视化 (图 9)。

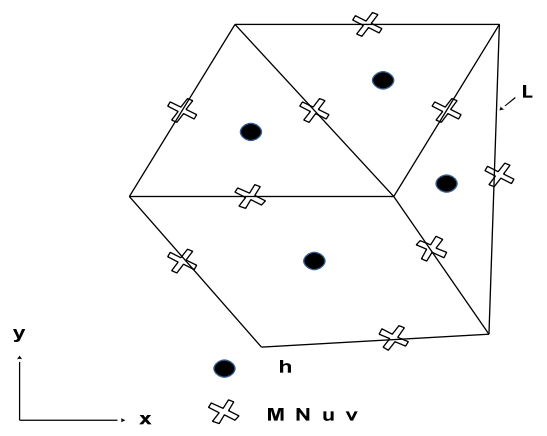

图 8.不规则网格模型

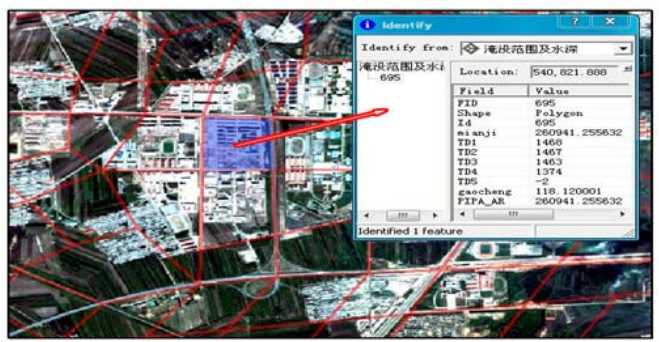

图 9. 城市暴雨积涝数值模拟可视化结果

\section{4. 情景设定}

情景模拟是通过人为假定的若干种情景，模拟 再现整个研究区内承灾体危险性变化情况, 以便更 好地预测未来灾情情况。情景模拟能够获得关于被 测对象更加全面的信息，对未来的预测、预警、应 急等至关重要。其情景设定应具有针对性、直接性、 可信性。由于情景模拟与现实较接近, 其结果可为 政府部门解决实际问题提供直观、可靠的数据信息。 情景模拟法研究过程中多数采用研究对象相关数据 为基础, 提取相关参数, 并以历史灾情数据分析结 果为基础设定不同情景，同时利用数学方法构建模
拟模型。

\section{1. 研究区暴雨现状与强度计算}

\section{4. 哈尔滨市暴雨现状}

根据国家气象局对暴雨的界定可以看出, 日 降水量 $\geq 50 \mathrm{~mm}$ 即为暴雨; 日降水量 $\geq 100 \mathrm{~mm}$ 为大 暴雨; 日降水量 $>250 \mathrm{~mm}$ 即为特大暴雨。市内全年 平均降水量 569. 1 毫米, 降水主要集中在 6-9 月, 夏季占全年降水量的 $60 \%$ 。四季分明, 冬季 1 月平 均气温约零下 19 度; 夏季 7 月的平均气温约 23 度。 哈尔滨市城区地势起伏, 极易造成城市积涝, 严重 影响城市交通和居民生活。依据哈尔滨市各个气象 台站 46 年的统计资料，哈尔滨市区每年发生 1.27 次暴雨, 具体哈尔滨市暴雨统计如图 10。

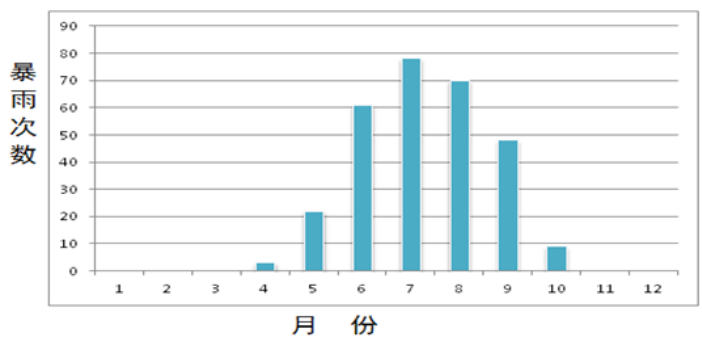

图 10. 哈尔滨市各月暴雨直方图

\section{5. 城市降雨强度计算}

降雨是积涝灾害的致灾源, 同时也是本研究中 积涝数值模型中的主要输入参数。通过对 1961-2010 年的历史降雨数据分析, 并结合哈尔滨市降雨模型 中的暴雨强度公式, 计算出哈尔滨市道里区降雨过 程中的任意时段内的平均降雨强度, 作为积涝数值 模型中的参数输入。表达式为:

$$
q=\frac{4800(1+\lg P)}{(t+15)^{0.98}}
$$

式中: $q$ 为暴雨强度; $P$ 为暴雨重现期; $t$ 为降水历 时。

\section{2. 情景分析及设定}

依据国家规定, 城市排水管网的即排能力应为 每秒 185 立方米, 这个排水能力可抵御中雨, 即每 小时 $25 \mathrm{~mm}$ 的降水量。可哈尔滨市排水管网的即排能 力为每秒 $117 \mathrm{~m}^{3}$, 比中雨的即排能力每秒低 $68 \mathrm{~m}^{3}$ 。也 就是说如果哈尔滨降中雨的话, 每秒就会有 $68 \mathrm{~m}^{3}$ 的雨水因无法即排而停留在路面上; 降雨超过半小 
时以上, 哈尔滨市的一些街道就会积水。依据情景 设定原则, 情景模拟式通过人为假定一系列情景, 模拟研究区整个评价区承灾体危险性变化情况, 以 便预测将来灾情局势。但对本研究区, 根据历史灾 情统计与分析结果得知: 5 年一遇暴雨产生积涝概 率较低; 100 年一遇暴雨发生概率较低, 一旦发生 100 年一遇暴雨, 则对研究区居民生命、财产安全 影响较大。所以, 本文暴雨积涝情景设定为 5 年、 100 年一遇的暴雨概率所导致的积涝情景 (图 11-12 图)。
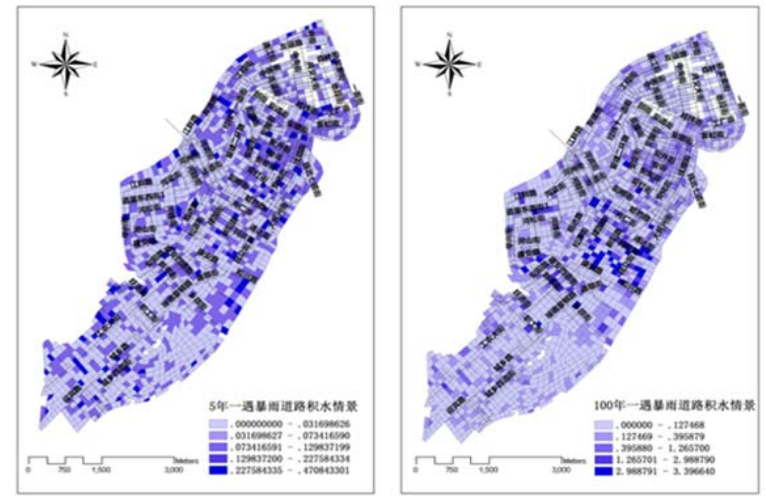

图 11. 5 年、100 年一遇暴雨道路积水情景
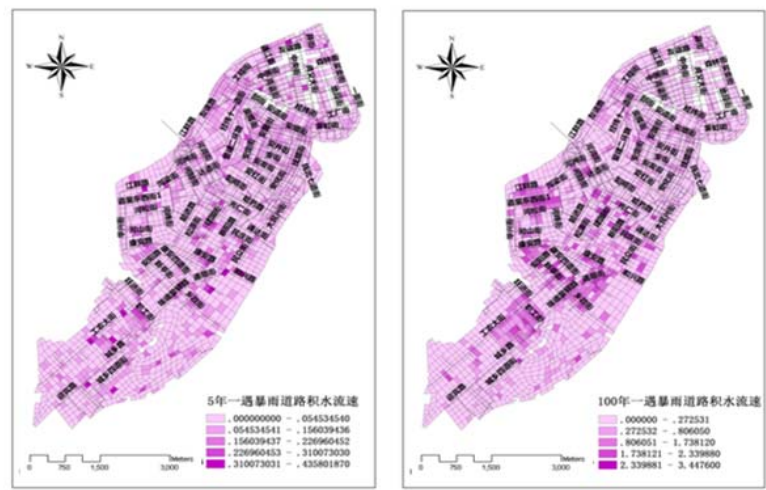

图 12.5 年、 100 年一遇暴雨道路积水流速

\section{5. 结论}

本文以城市频发的暴雨积涝灾害为研究对象, 结合哈尔滨道里区为实证研究, 提出了一套基于信 息扩散理论的小尺度的城市暴雨积涝数值模型构建 与情景模拟思路与方法。研究结果如下:

(1) 以 GIS 技术为基础数据平台, 以一、二维 非恒定流为模型基本控制方程, 以不规则网格为基 本骨架, 构建了基于 “三层空间（空中降雨-下垫面
-排水管网)”的城市暴雨积涝数值模拟模型;

(2) 以研究区暴雨强度计算结果为基础, 作为 积涝数值模型的初始输入参数, 并结合历史暴雨资 料分析结果发现: 5 年一遇暴雨发生概率较高; 100 年一遇暴雨发生概率较低, 但 100 年一遇暴雨发生 对研究区影响较大;

(3) 依据上述两方面研究结果, 结合 GIS 技术 实现了不同情景下暴雨积涝情景模拟。模拟结果表 明当研究区发生 5 年一遇的暴雨时区内刚好发生积 涝灾害, 且水深为 $0-0.47 \mathrm{~m}$ 之间, 流速在 0-0.43m/s 之间; 100 年一遇的暴雨时区内积涝为最大, 且水 深在 0-3m 之间, 流速在 0-3.4m/s 之间。

由于城市暴雨积涝灾害系统是个复杂系统, 受 多变量因素所制约, 导致在数值模型构建及模拟过 程中精度问题会随着地形变化而变化, 因此, 本文 采用的城市暴雨积涝数值模型构建过程与方法在哈 尔滨市道里区已得到验证, 但移植到其他城市区域 需进行模型参数重新校正。

\section{致谢}

本项研究得到了下列基金项目的资助：国家自然 科学基金(41371495); 国家科技支撑计划课题(2013B AK05B01); 国家科技支撑计划课题(2013BAK 05B02); 吉林省科技厅项目 $(20150520081 \mathrm{JH})$; 吉林省自然科学 基金项目(201215224); 四平市社会科学基金项目的编 号(201118)。

\section{参考文献}

[1] Chen peng, Zhang Jiquan, Jiang Xinyu, Liu Xingpeng, BaoYulong, Sun Yingyue. Scenario simulation-based assessment of trip difficulty for urban residents under rainstorm waterlogging. International Journal of Environmental Research and Public Health. 2012, 9(6): 2057-2074.

[2] 朱强,孙敏,陈秀万, 等. 基于动态数字地形模型的流域产 汇流模拟方法术. 北京大学学报(自然科学版), 2009, 45(5): 805-810.

[3] 张萍萍, 王丽, 张宁. 武汉市城市积涝预警系统及其仿真 模拟效果. 暴雨灾害, 2010, 29(1): 71-75.

[4] 仇劲文,李娜,程晓陶,等.天津市城区暴雨沥涝仿真模拟 系统. 水利学报, 2000 (11), 34-42.

[5] 解以扬, 李人鸣, 李培彦. 城市暴雨内涝数学模型的研究 与应用. 水科学进展, 2005, 16(3) :384-390.

[6] 尹占娥, 许世远, 殷杰, 等. 基于小尺度的城市暴雨内涝灾 害情景模拟与风险评估。地理学报, 2010, 65(5):554-557.

[7] Theo G S, Martin T, Norman E. Analysis and modeling of fooding in urban drainage systems. Journal of Hydrology, 2004, 299(3): 300-311. 
[8] Black J, Endreny $T$ A. Increasing stormwater outfal duration, magnitude, and volume through combined sewer separation. Journal of Hydrologic Engineering, 2006,11(5):472-481.

[9] Zaghloul N A. Flow simulation in circular pipes with variable roughness using SWMM EXTRAN mode. Journal of Hydrographic Engineering, 1998, 124(1):73-76

[10] 李娜,仇劲卫,程晓陶,等.天津市城区暴雨沥涝仿真模拟 系统的研究.自然灾灾害学报,2002.11(2):113-118.

[11] 解以扬,李大鸣,沈树勤, 等. “030704” 南京市特大暴雨 内涝灾害的仿真模拟. 长江科学学院 报,2004,21(6):73-76

[12] 尹占娥,许世远,殷杰,等.基于小尺度的城市暴雨内涝灾 害情景模拟与风险评估.地理学报,2010,65(5):554-557.
[13] 景垠娜,尹占娥,殷杰, 等. 基于 GIS 的上海浦东新区暴雨 内涝灾害危险性分析.灾害学,2010,25(2):58-63.

[14] 刘仁义,刘南.基于 GIS 的复杂地形洪水淹没区计算方 法.地理学报,2001,56(1):1.6.

[15] 刘仁义,刘南.基于 GIS 的复杂地形洪水淹没区计算方 法.地理学报,2001,56(1):1.6.

[16] 郭利华,龙毅. 基于 DEM 的洪水淹没分析.测绘通 报,2002,5(11):25.30.

[17] 权瑞松,刘敏,等.基于简化内涝模型的上海城区内涝危 险性评价.人民长江,2010,41(2): 33-34.

[18] 程晓陶,杨磊,陈喜军.分蓄洪区洪水演进模型. 自然灾害 学报, 1996,5(1):34-40.

[19] 黄崇福.模糊信息优化处理技术及其应用].北京：北京 航空航天大学出版社,1995. 